\title{
Densification, Microhardness and Microestructural Evolution by Fast Low- Temperature Consolidation of AlxCoCrFeMnNi High Entropy Alloy
}

M.A. Ruiz-Esparza-Rodriguez ${ }^{1}$, C.G. Garay-Reyes ${ }^{1}$, J. M. Mendoza-Duarte ${ }^{1}$, I. Estrada-Guel ${ }^{1}$ and R. Martinez-Sanchez ${ }^{1}$.

${ }^{1}$ Centro de Investigación en Materiales Avanzados (CIMAV), Laboratorio Nacional de Nanotecnología, Miguel de Cervantes 120, 31136 Chihuahua, Chih., México.

High entropy alloys (HEA's) have been investigated for their attractive mechanical, microstructural and thermal properties. HEA's representing a wide field of study, usually these alloys are synthetized by different techniques like an arc casting, conventional sintering, plasma sintering and conventional casting $[1,2]$. A new alternative consolidation route based in high frequency induction is proposes in this work, such route will provide the option to consolidate HEA at low temperature and short time, and allowing control porosity and oxidation. Thus, this work evaluates the densification, microstructure, microhardness and the aluminum addition in samples obtained by the new, fast, and low temperature consolidation process. The results are compared with conventional consolidation method

The elemental powders of $\mathrm{Al}, \mathrm{Co}, \mathrm{Cr}, \mathrm{Fe}, \mathrm{Mn}$, and $\mathrm{Ni}$ with purity higher than $99.5 \%$ were mechanically alloyed to form AlxCoCrFeMnNi high entropy alloy with different $\mathrm{Al}$ contents $(\mathrm{x}=0.5,1$ and 1.5) using a high energy mill Spex 8000. Milling media and container are done by hardened steel. Milling conditions were set to $10 \mathrm{~h}$ of milling time, powder mass $8.5 \mathrm{~g}$ and a ball-to-powder ratio of 5:1. Nheptane was used as process control agent. To prevent contamination, the milling was performed under Ar atmosphere. 2 different routes were used in consolidation process of the powders. The first one was uniaxial pressing with the following conditions: the compaction pressure was $1.56 \mathrm{GPa}$ for $10 \mathrm{~min}$, followed by the sintered at $1200^{\circ} \mathrm{C}$ for $3 \mathrm{~h}$. The second one was the fast-low temperature (FLT) consolidation with the following conditions: compacted and pre-sinterized were performed simultaneously under compaction pressure of $0.9 \mathrm{GPa}$ at $600^{\circ} \mathrm{C}$ for $3 \mathrm{~min}$ using a high frequency induction furnace, followed by a conventional sintering at $1200^{\circ} \mathrm{C}$ for $3 \mathrm{~h}$. The density of the samples was calculated using the Archimedes method in analytical balance Sartorius CP2250. The microstructural characterization was carried out by scanning electron microscope HITACHI SU3500. The Vickers microhardness was evaluated in LM300 AT tester.

The density obtained indicates that the conventional method (figure 1a) achieves a lower densification than the FLT method (figure $1 \mathrm{~b}$ ). The SEM micrographs in figure 2 are in agreement with the density results. Also shown a reduction of pores-oxides in the case of FLT method in addition present a best diffusion process of elements and higher microhardness values using the new route proposed in comparison to conventionally sintering. In conclusion it was determined that FLT consolidation achieves a greater reduction of porosity-oxides and presents higher hardness values given that there is a matrix with greater homogeneity compared to the conventional consolidation method.

References:

[1] Ye. Y.F, Wang. Q, Lu. J, Liu. C.T,Yang. Y, High-entropy alloy: challenges and prospects, (2016), Volume 19, Issue 6, p. 349-362.

[2] Cantor. B, Multicomponent and High Entropy Alloys, (2014) Entropy, Volume 16(9), p, 4749-4768. 


\section{a) Conventional Consolidation}

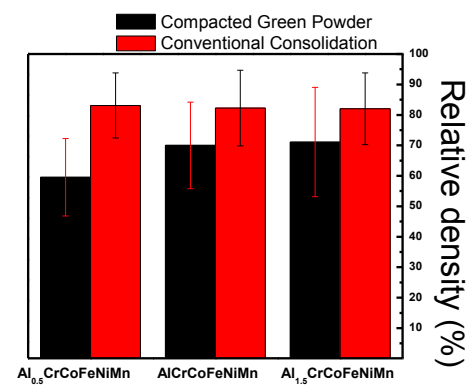

b) Fast-Low Consolidation

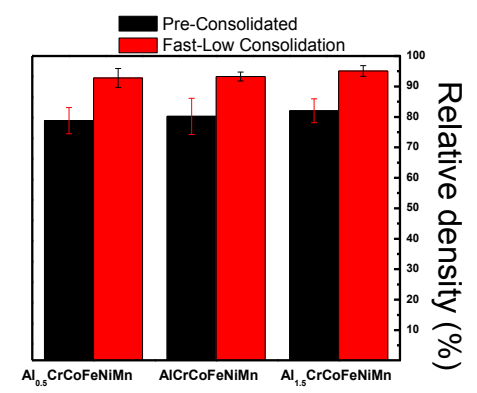

Figure 1. Relative density obtained in AlxCoCrFeMnNi high entropy alloys with different $\mathrm{Al}$ contents $(\mathrm{x}=0.5,1$ and 1.5$)$ for conventional consolidated and fast-low consolidation conditions.

Pre-Consolidation

Conventional Consolidation

Fast Low-Consolidation

\section{Alo.5CoCrFeMnNi}
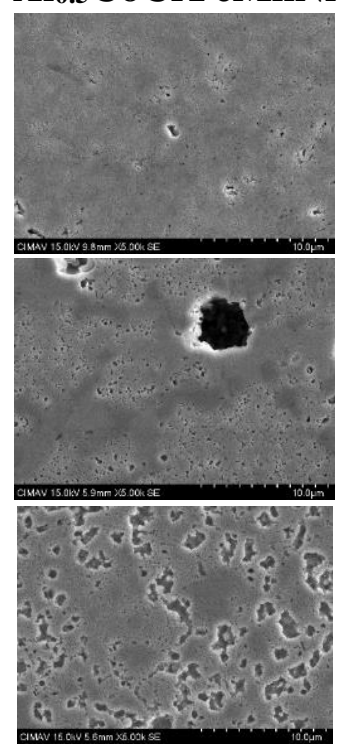

$\mathrm{AlCoCrFeMnNi}$
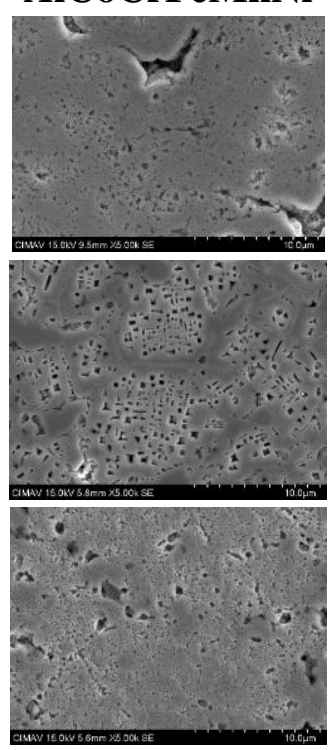
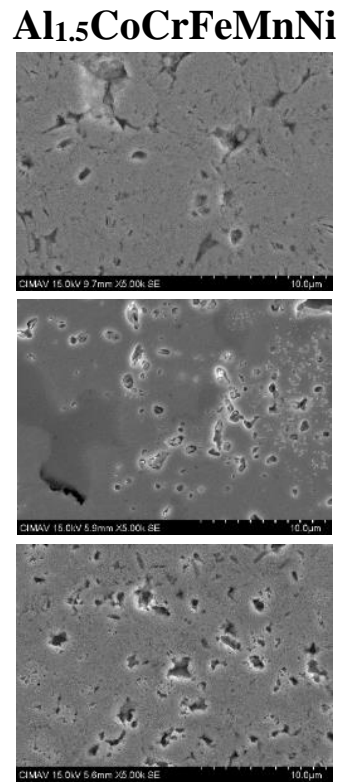

Figure 2. SEM Micrographs obtained in $\mathrm{AlxCoCrFeMnNi} \mathrm{high} \mathrm{entropy} \mathrm{alloys} \mathrm{with} \mathrm{different} \mathrm{Al}$ contents $(\mathrm{x}=0.5,1$ and 1.5$)$ for pre-consolidation, conventional consolidation and fast-Low consolidation conditions.

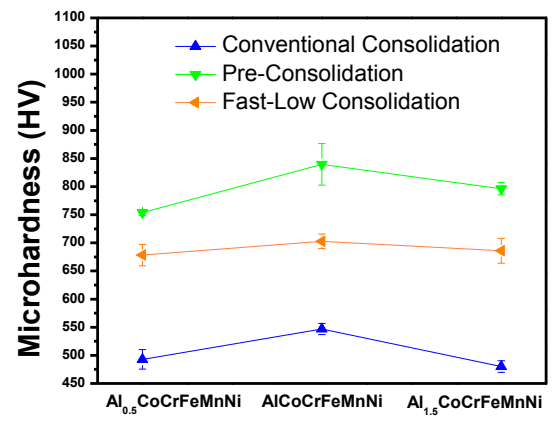

Figure 3. Vickers microhardness values obtained in AlxCoCrFeMnNi high entropy alloys with different Al contents $(\mathrm{x}=0.5,1$ and 1.5$)$ for pre-consolidation, conventional consolidation and fast-Low consolidation conditions. 